\title{
The Role of Ursodeoxycholic Acid and Phenobarbital in a Child with Cholestasis: A Longitudinal Study
}

\author{
Harapan Parlindungan Ringoringo* (B) \\ Department of Child Health, Faculty of Medicine, Lambung Mangkurat University, RSD Idaman Banjarbaru, Banjarbaru, \\ Indonesia
}

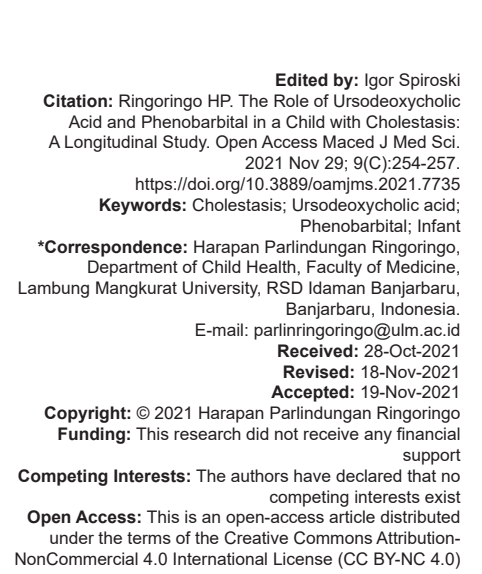

\section{Abstract}

BACKGROUND: Cholestasis is a condition that starts in the $1^{\text {st }}$ months of life and progresses with direct (conjugated) bilirubin increase and jaundice as a result of impaired bile production or excretion. Its incidence is known as 1 in 2500 live births. This study shows the effectiveness of ursodeoxycholic acid (UDCA) and phenobarbital in infant cholestasis treatment.

CASE REPORT: A 28-days-old boy came with a complaint of yellow eyes. At the age of 3 days, the patient looked yellow, had a fever and difficulty drinking, received phototherapy. After 2 weeks of treatment with neonatal sepsis, the patient was discharged in a stable. The skin appears yellow. The laboratory results show anemia, elevated conjugated bilirubin, and signs of infection; the abdominal ultrasonography shows that the liver and gallbladder were normal. The diagnosis is cholestasis due to sepsis. After 3 months of treatment with UDCA and phenobarbital, jaundiced disappeared, and liver function tests were normal. When the patient is $2 \frac{1}{2}$ years old, the growth and development suit his age.

CONCLUSION: Early diagnosis and timely treatment of UDCA and phenobarbital play a role in cholestasis improvement. On long-term observation, the child's growth and development are suitable according to his age and average laboratory results.

\section{Introduction}

Any infant who has jaundice for more than 2-3 weeks should consider the presence of neonatal cholestasis. The incidence is 1:2500 live births [1]. Cholestasis is the accumulation of bile substances in the blood due to impaired excretion. Therefore, it is necessary to check for direct (conjugated) and indirect (unconjugated) bilirubin in this situation. Elevated indirect bilirubin generally resolves spontaneously or with phototherapy. On the other hand, conjugated hyperbilirubinemia is never physiological or normal. Elevated direct bilirubin, pale stools, and dark urine are the main signs of neonatal cholestasis. It is cholestasis when the conjugated bilirubin level is above $1 \mathrm{mg} / \mathrm{dL}$ when the total serum bilirubin level is below $5 \mathrm{mg} / \mathrm{dL}$, or conjugated bilirubin is more than $20 \%$ of the total when the total bilirubin level is above $5 \mathrm{mg} / \mathrm{dL}$ [2].

In a large-scale study conducted in the United States, cholestasis due to infection was $11.5 \%$ (194/1692) [3]. Cholestasis may also accompany bacterial sepsis. Mediators caused by bacterial products and endotoxins cause cholestasis, which leads to changes in hepatic circulation and decreases bile flow. In one study, the most common cause of cholestasis was sepsis, and cholestasis occurred on average on day $10^{\text {th }}$ of infection [4]. This study aims to show that ursodeoxycholic acid (UDCA) and phenobarbital are effective in cholestasis management.

\section{Case Report}

A28-days-old boy, with $3.1 \mathrm{~kg}$ and length $51 \mathrm{~cm}$, came with the chief complaint of yellow eyes and body. At the age of 3 days, the patient looked yellow, had a fever and difficulty drinking, received phototherapy. After 2 weeks of treatment with neonatal sepsis, the patient was discharged in a stable condition. On physical examination, the sclera was yellow, and the conjunctiva was pale. The skin appears yellow, on a scale of 3 , according to Kramer. The palms and soles of the feet look pale. Laboratory results: hemoglobin $(\mathrm{Hb}) 10.7 \mathrm{~g} /$ dL, leukocytes $13,700 / \mathrm{LL}$, platelets $305,000 / \mathrm{LL}$ red blood cell count (RBC) 3.95 million/uL, mean corpuscular volume (MCV) $80.3 \mathrm{fL}$, mean corpuscular $\mathrm{Hb}(\mathrm{MCH})$ 27.1 pg, Mentzer index 20.3, erythrocyte sedimentation rate (ESR) $1 \mathrm{~h} 25 \mathrm{~mm}, 2 \mathrm{~h} 47 \mathrm{~mm}$, and C-reactive protein (CRP) (+) $48 \mathrm{mg} / \mathrm{L}$. Aspartate aminotransferase (AST): 
$338 \mathrm{U} / \mathrm{L}$, alanine aminotransferase (ALT): $125 \mathrm{U} / \mathrm{L}$, total bilirubin: $11.71 \mathrm{mg} / \mathrm{dL}$, direct bilirubin: $4.5 \mathrm{mg} / \mathrm{dL}$, indirect bilirubin: $7.21 \mathrm{mg} / \mathrm{dL}$, Gamma-glutamyl transferase (GGT)159 U/L, and alkaline phosphatase $357 \mathrm{U} / \mathrm{L}$. Ultrasound (USG): The liver and gallbladder were normal. The diagnosis is cholestasis due to sepsis, and iron deficiency anemia. The patient was treated with cefixime $10 \mathrm{mg} / \mathrm{kg} / \mathrm{day}$ in two divided doses for 5 days and elemental iron $9 \mathrm{mg}$ for 3 months. Patients also receive a multivitamin containing Vitamins $A, D, E$, $\mathrm{K}, \mathrm{B}$, and $\mathrm{C}$ until 1 year. After 3 months of treatment with UDCA $15 \mathrm{mg} / \mathrm{kg} /$ day, in three divided doses and phenobarbital $10 \mathrm{mg} / \mathrm{kg} / \mathrm{day}$, in three divided doses, the jaundiced disappear and total bilirubin: $0.34 \mathrm{mg} / \mathrm{dL}$, direct bilirubin: $0.11 \mathrm{mg} / \mathrm{dL}$, indirect bilirubin: $0.23 \mathrm{mg} / \mathrm{d}$, AST: $53 \mathrm{U} / \mathrm{L}$, and ALT: $25 \mathrm{U} / \mathrm{L}$. When the patient is 2 $1 / 2$ years old, total bilirubin: $0.08 \mathrm{mg} / \mathrm{dL}$, direct bilirubin: $0.07 \mathrm{mg} / \mathrm{dL}$, indirect bilirubin: $0.01 \mathrm{mg} / \mathrm{d}$, AST: $39 \mathrm{U} / \mathrm{L}$, and ALT: $10 \mathrm{U} / \mathrm{L}$. Hb $12.3 \mathrm{~g} / \mathrm{dL}$, RBC 5.3 million/uL, MCV $70.9 \mathrm{fL}$, and Mentzer index 13.3. On long-term observation, the child's growth and development are suitable according to his age and average laboratory results. The growth chart weight-for-age of the patient is shown in Figure 1.

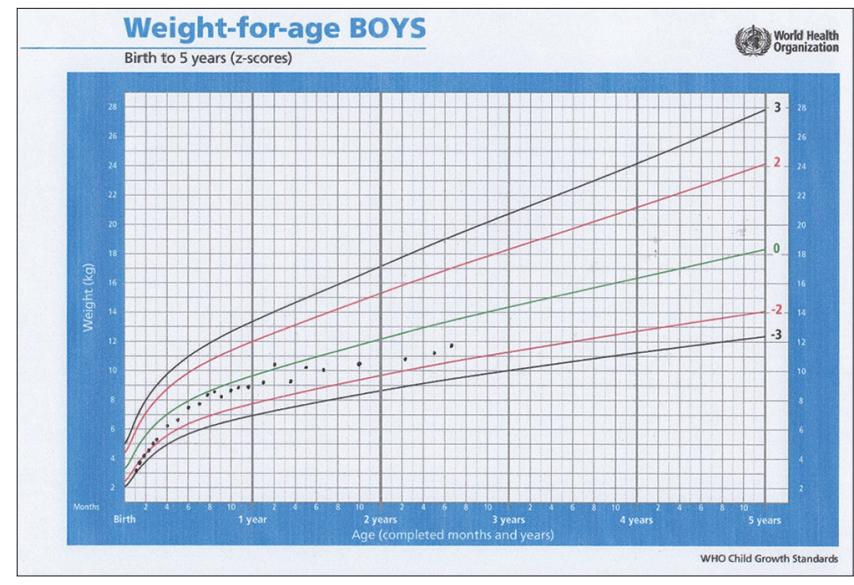

Figure 1: The growth chart weight-for-age of the patient

\section{Discussion}

Neonatal cholestasis is a condition that starts in the $1^{\text {st }}$ months. As a result of increased conjugated bilirubin and bile acids, toxin components cause liver damage and cause hepatobiliary dysfunction. Therefore, in a patient presenting with jaundice, it is critical to distinguish whether the jaundice is cholestatic or not. The median age of onset of jaundice was 6 days [5]. Early and accurate diagnosis of neonatal cholestasis patients is very important for treatment success and prognosis. Evaluation of these patients is difficult due to the variety of cholestatic syndromes and the lack of clinical manifestations specific to diseases [2].
The most common cause of neonatal cholestasis is intrahepatic cholestasis, and then extrahepatic cholestasis. In one study of 131 patients, $99(75.6 \%)$ patients were in the intrahepatic cholestasis group. Meanwhile, 32 (24.4\%) patients were in the extrahepatic cholestasis group. In the intrahepatic cholestasis group, total parenteral nutrition-related cholestasis $(27.3 \%)$ was the most common, and biliary atresia $(71.9 \%)$ was the most common in the extrahepatic cholestasis group. Other main reasons were systemic $(19.1 \%)$, metabolic $(12.2 \%)$, hereditary cholestatic diseases $(9.9 \%)$, and infectious $(7.6 \%)$ causes [5].

In this case, the diagnosis is cholestasis due to sepsis and iron deficiency anemia. The presence of jaundice established cholestasis until the age of 28 days with a direct bilirubin level of $4.5 \mathrm{mg} / \mathrm{dL}, 38.4 \%$ of total bilirubin $11.71 \mathrm{mg} / \mathrm{dL}$, and more than $20 \%$ of total bilirubin > $5 \mathrm{mg} / \mathrm{dL}$ [2]. USG Abdomen: The liver and gallbladder were normal. Bacterial infection, in this case, was characterized by leukocytes $13,700 / \mathrm{uL}$, ESR 1 h $25 \mathrm{~mm}, 2$ h $47 \mathrm{~mm}$, and CRP (+) $48 \mathrm{mg} / \mathrm{L}$. Iron deficiency anemia was established based on pale conjunctiva, pale palms, and soles with $\mathrm{Hb}$ $10.7 \mathrm{~g} / \mathrm{dL}, \mathrm{RBC} 3.95$ million/uL, MCV $80.3 \mathrm{fL}, \mathrm{MCH}$ $27.1 \mathrm{pg}$, Mentzer index $>20$.

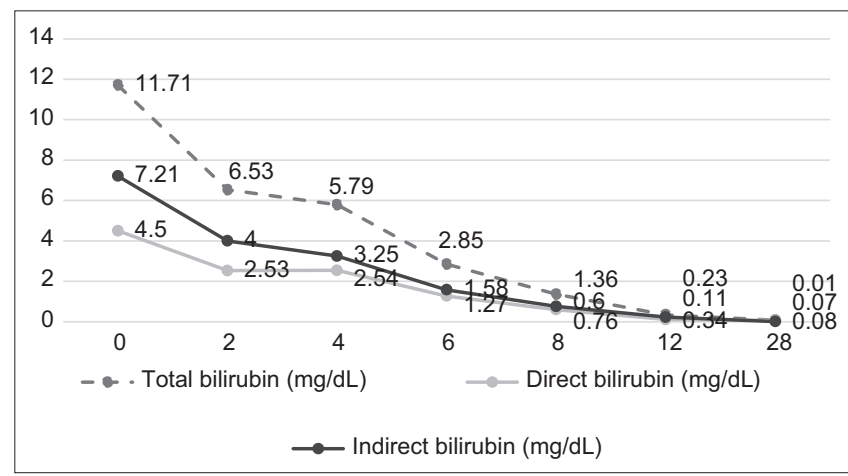

Figure 2: The changes of bilirubin after 12 weeks of therapy with ursodeoxycholic acid and phenobarbital

In this case, the infection was treated with cefixime $10 \mathrm{mg} / \mathrm{kg} /$ day in two divided doses for 5 days. As a result, the patient's clinical condition improved. After the infection resolved, the patient also received elemental iron $9 \mathrm{mg} / \mathrm{kg} /$ day for 3 months to treat IDA. After 3 months (12 weeks) of the treatment with UDCA $15 \mathrm{mg} / \mathrm{kg} /$ day, in three divided doses and phenobarbital $10 \mathrm{mg} / \mathrm{kg} /$ day, in three divided doses, the jaundiced disappear, and total bilirubin: $0.34 \mathrm{mg} / \mathrm{dL}$, direct bilirubin: $0.11 \mathrm{mg} / \mathrm{dL}$, indirect bilirubin: $0.23 \mathrm{mg} / \mathrm{d}, \mathrm{AST}$ : $53 \mathrm{U} / \mathrm{L}$, and ALT: $25 \mathrm{U} / \mathrm{L}$. The liver function test changes after 12 weeks of therapy with UDCA and phenobarbital are shown in Figures 2 and 3.

UDCA can be a hepatoprotector and can improve the patient's clinical condition. UDCA has been widely researched and has various benefits for the liver to protect the liver from various toxins 


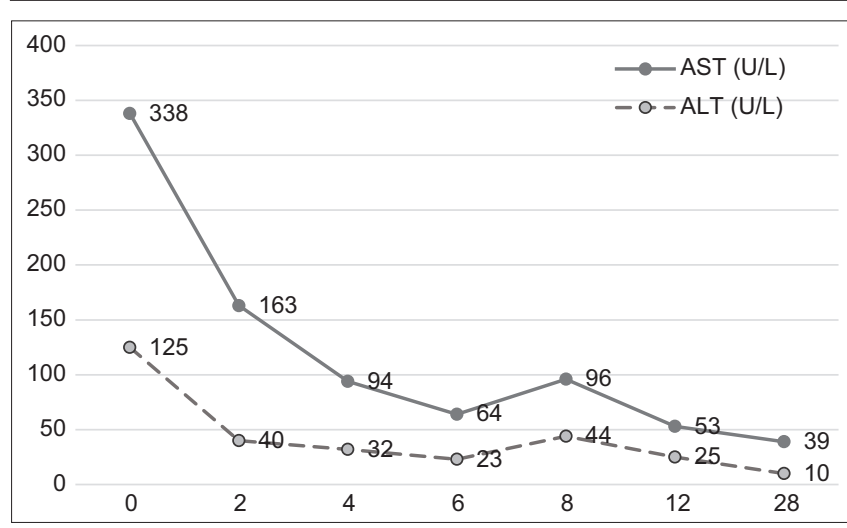

Figure 3: The changes of aspartate aminotransferase and alanine aminotransferase after 12 weeks of therapy with ursodeoxycholic acid and phenobarbital

and free radicals. UDCA's various mechanisms are anti-inflammatory action, immunomodulatory, cytoprotective, and anti-apoptotic action, choleretic action, coordination of mitochondrial integrity, and alteration of cell signaling [6], [7], [8]. UDCA has been found to have beneficial effects on many forms of cholestasis. It is commonly used as first-line therapy for pruritus due to cholestasis. In addition, it is used for parenteral nutrition-induced cholestasis, biliary atresia after surgical treatment, and 1 antitrypsin deficiency.

Its mode of action is not fully understood but appears to have two components: (a) Substitution in the bile acid pool for the more hepatotoxic hydrophilic bile acids, and (b) stimulation of bile flow. The dosage is $20-30 \mathrm{mg} / \mathrm{kg} /$ day in three divided doses [9]. The only common side effect of UDCA is diarrhea which usually goes away once UDCA is stopped. Likewise, UDCA can be discontinued once the cholestasis has resolved [10].

One study found UDCA to have a hepatoprotective effect by significantly lowering liver function levels, namely, ALT ( $p=0.0002)$, AST $(p<0.0001)$, GGT $(p<0.0001)$, alkaline phosphatase $(p<0.0001)$, and bilirubin $(p=0.04)$. The results of this meta-analysis demonstrated the hepatoprotective effect of UDCA by reducing liver function values [11]. A study studied 168 patients with impaired liver function and fatty liver. It turned out that the group that was given UDCA for 8 weeks compared with the control showed significant clinical and laboratory improvement $(p<0.05)$ [12]. Other studies have shown that UDCA can reduce levels of serum glutamic oxaloacetic transaminase, serum glutamyl pyruvate transaminase, and GGT in hepatitis C patients [13].

Phenobarbital stimulates bile acid flow, increases bile acid synthesis, induces liver microsomal enzymes, and, therefore, decreases circulating bile acid levels. The side effects of phenobarbital that cause sedation and behavioral disturbances limit its use. The usual dose of phenobarbital is 3-10 mg/kg/day [14].

Infants with cholestasis often present steatorrhea and increased energy expenditure.
Therefore, caloric intake should be approximately $125 \%$ of the recommended dietary allowance (RDA) based on ideal body weight [15], [16]. Intestinal absorption of fatsoluble Vitamins $(A, D, E$, and $K)$ requires the presence of bile acids. Therefore, the vitamin dose is at least 2-4 times the recommended daily requirement RDA. Vitamin supplementation should be continued for at least 3 months after icterus has disappeared [2]. In this case, a multivitamin containing Vitamins $A, D, E, K, B$, and $C$ is given until the patient is 1 year old.

In long-term observation, the growth and development of patients are suitable according to their age. At the age of 2 years and 6 months, the laboratory results showed promising results. Total bilirubin $0.08 \mathrm{mg} / \mathrm{dL}$, direct bilirubin $0.07 \mathrm{mg} / \mathrm{dL}$, indirect bilirubin $0.01 \mathrm{mg} / \mathrm{dL}$, AST $39 \mathrm{U} / \mathrm{L}$, and ALT $10 \mathrm{U} / \mathrm{L}$; and the patient is not anemic. This long-term observation means that if we can diagnose cholestasis early and the treatment given is adequate and appropriate, the prognosis will be as good as in this patient.

\section{Conclusion}

Early diagnosis and timely treatment of UDCA and phenobarbital play a role in cholestasis improvement. On long-term observation, the child's growth and development are suitable according to his age and average laboratory results.

\section{References}

1. Dick MC, Mowat AP. Hepatitis syndrome in infancy--an epidemiological survey with 10 year follow up. Arch Dis Child. 1985;60(6):512-6. https://doi.org/10.1136/adc.60.6.512 PMid:3874604

2. Feldman AG, Sokol RJ. Neonatal cholestasis. Neoreviews. 2013;14(2):e63-73. https://doi.org/10.1542/neo.14-2-e63 PMid:24244109

3. Gottesman LE, Del Vecchio MT, Aronoff SC. Etiologies of conjugated hyperbilirubinemia in infancy: A systematic review of 1692 subjects. BMC Pediatr. 2015;15:192. https://doi. org/10.1186/s12887-015-0506-5 PMid:26589959

4. Tiker F, Tarcan A, Kilicdag H, Gürakan B. Early onset conjugated hyperbilirubinemia in newborn infants. Indian $\mathrm{J}$ Pediatr. 2006;73(5):409-12. https://doi.org/10.1007/BF02758562 PMid:16741326

5. Sağ E, Öztürk EE, Yalçın Cömert HS, Arslan Y, Karahan SC Çakır M. Retrospective evaluation of the neonatal cholestasis cases. J Acad Res Med. 2021;11:90-6

6. IkegamiT,MatsuzakiY.Ursodeoxycholicacid:mechanismofaction and novel clinical applications. Hepatol Res. 2008;38(2):123-31. https://doi.org/10.1111/j.1872-034X.2007.00297.x

PMid:18034825 
7. Saksena S, Tandon RK. Ursodeoxycholic acid in the treatment of liver diseases. Postgrad Med J. 1997;73(856):75-80. https:// doi.org/10.1136/pgmj.73.856.75

\section{PMid:9122101}

8. Kriegermeier A, Green R. Pediatric cholestatic liver disease Review of bile acid metabolism and discussion of current and emerging therapies. Front Med. 2020;7:1-15. https://doi. org/10.3389/fmed.2020.00149

PMid:32432119

9. Chen CY, Tsao PN, Chen HL, Chou HC, Hsieh WS, Chang $\mathrm{MH}$. Ursodeoxycholic acid (UDCA) therapy in very-low-birthweight infants with parenteral nutrition-associated cholestasis. J Pediatr. 2004;145(3):317-21. https://doi.org/10.1016/j. jpeds.2004.05.038

PMid: 15343182

10. Hempfling W, Dilger K, Beuers U. Ursodeoxycholic acidadverse effects and drug interactions. Alimentary pharmcology and therapeutics. Aliment Pharmacol Ther. 2003;18(10):963-72. https://doi.org/10.1046/j.1365-2036.2003.01792.x PMid: 14616161

11. Simental-Mendía M, Sánchez-García A, Simental-Mendía LE. Effect of ursodeoxycholic acid on liver markers: A systematic review and meta-analysis of randomized placebo-controlled clinical trials. Br J Clin Pharmacol. 2020;86(8):1476-88. https:// doi.org/10.1111/bcp.14311

PMid:32285958

12. Oh B, Choi WS, Park SB, Cho B, Yang YJ, Lee ES, et al Efficacy and safety of ursodeoxycholic acid composite on fatigued patients with elevated liver function and/or fatty liver: A multi-centre, randomised, double-blinded, placebo-controlled trial. Int J Clin Pract. 2016;70(4):302-11. https://doi.org/10.1111/ ijcp. 12790 PMid:26997458

13. Sato S, Miyake T, Tobita H, Oshima N, Ishine J, Hanaoka T, et al. A dose-up of ursodeoxycholic acid decreases transaminases in hepatitis C patients. World J Gastroenterol WJG. 2009;15(22):2782. https://doi.org/10.3748/wjg.15.2782 PMid:19522030

14. McKiernan PJ. The infant with prolonged jaundice: Investigation and management. Curr Paediatr. 2001;11:83-9.

15. De Bruyne R, Van Biervliet $S$, Vande Velde $S$, Van Winckel M Clinical practice. Eur J Pediatr. 2011;170:279-84. https://doi. org/10.1007/s00431-010-1363-8

16. Venigalla S, Gourley GR. Neonatal cholestasis. Semin Perinatol. 2004;28(5):348-55. https://doi.org/10.1053/j. semperi.2004.09.008

PMid:15686266 